\title{
Amitriptyline Reduces Inflammation and Mortality in a Murine Model of Sepsis
}

\author{
Brent T. Xia ${ }^{a}$ Nadine Beckmann ${ }^{a} \quad$ Leah K. Winer $^{\mathrm{a}} \quad$ Amanda M. Pugh ${ }^{\mathrm{a}}$ \\ Timothy A. Pritts ${ }^{a} \quad$ Vanessa Nomellini ${ }^{a} \quad$ Erich Gulbins ${ }^{a, b} \quad$ Charles C. Caldwell ${ }^{a, c}$ \\ aDivision of Research, Department of Surgery, College of Medicine, University of Cincinnati, Cincinnati, \\ $\mathrm{OH}$, USA, bDepartment of Molecular Biology, University Hospital, University of Duisburg-Essen, Essen, \\ Germany, 'Division of Research, Shriners Hospital for Children, Cincinnati, OH, USA
}

\section{Key Words}

Sepsis $•$ Amitriptyline $\cdot$ Macrophage $・ I L-10 \cdot p 38$

\begin{abstract}
Background/Aims: During sepsis, an unchecked pro-inflammatory response can be detrimental to the host. We investigated the potential protective effect of amitriptyline (AT). Methods: We used two murine models of sepsis: Cecal ligation and puncture and endotoxemia following LPS challenge. Aural temperatures were taken and cytokines quantified by cytometric bead assay. Lung injury was determined histologically and by protein determination in bronchoalveolar lavage fluid. Cell accumulation in the peritoneum was analyzed by flow cytometry, as well as cytokine production and p38-phosphorylation. Neutrophil chemotaxis was evaluated using an in vitro transwell assay. Results: Our findings demonstrate that AT-treated septic mice have improved survival and are protected from pulmonary edema. Treatment with AT significantly decreased serum levels of KC and monocyte chemoattractant protein-1, as well as the accumulation of neutrophils and monocytes in the peritoneum of septic mice. Peritoneal IL-10 levels in septic mice were increased upon AT treatment. Direct treatment of septic mice with IL-10 recapitulated the effects of AT. Endotoxemic mice also exhibited enhanced IL-10 production upon AT-administration and peritoneal macrophages were identified as the ATinfluenced producers of IL-10. Treatment of these cells with AT in vitro resulted in increased p38-phosphorylation and IL-10 generation, whereas ceramide and p38 inhibition had the opposite effect. Conclusion: Altogether, AT treatment improved survival, increased IL-10 levels, and mitigated a pro-inflammatory response during sepsis. We conclude that AT is a promising therapeutic to temper inflammation during septic shock.
\end{abstract}




\section{Introduction}

Among hospitalized patients diagnosed with sepsis or septic shock, the mortality secondary to sepsis-related complications approaches 25\% [1]. Timely initiation of critical care, including early antibiotic administration, has been shown to significantly decrease mortality rates $[2,3]$. However, despite these interventions, sepsis deaths have increased within the past decade [4].

Macrophages are among the first responders to the septic insult and can produce a number of cytokines, including pro-inflammatory tumor necrosis factor alpha (TNF $\alpha$ ) but also anti-inflammatory IL-10. The balance between pro- and anti-inflammatory cytokines released after insult influences the extent of inflammation during sepsis and the outcome. Increased IL-6:IL-10 ratios are seen in non-survivors 48 hours after onset of sepsis [5]. When the initial host response causes exaggerated inflammation, this can result in tissue injury and may progress further to single- or multi-organ dysfunction [6], even if the infectious source is controlled with antibiotics. Thus, the hyper-inflammatory response may still give way to the lethal sequelae of tissue injury, multi-organ dysfunction and death.

Previous work from our group demonstrates that AT has anti-inflammatory effects in scald-injured mice [7] and mitigates sepsis-induced TNF $\alpha$ expression and coagulation in a mouse model of sepsis [8]. Furthermore, Peng et al. have demonstrated that AT mitigates superoxide formation, which normally results in the breakdown of tissue tight junction proteins during Staphylococcus aureus (S. aureus) sepsis [9]. Regarding cytokines, ATadministration for 4 weeks has been reported to increase splenic IL-10 levels in mice [10] and in in vitro studies, AT mitigated IL-1ß and TNF $\alpha$ production by macrophages in response to $S$. aureus $\alpha$-toxin [11]. Taken together, these data highlight a potential therapeutic benefit of AT treatment in sepsis.

Mechanistically, AT has been reported to upregulate microglia p38 mitogen-activated protein kinase activity and IL-10 expression in chronically morphine-infused rats [12]. However, the impact of AT-treatment in the context of sepsis is relatively unexplored. Altogether, we postulated that AT-treatment during sepsis may also result in increased IL-10 generation, potentially ameliorating the early pro-inflammatory response associated with sepsis.

\section{Materials and Methods}

\section{Ethical statement}

All murine experiments were approved by the Institutional Animal Care and Use Committee of the University of Cincinnati (protocol number: 08-09-19-01).

\section{Mouse housing}

Male CF-1 outbred mice aged 6-8 weeks (Charles River Laboratories, Wilmington, MA) were used for experiments. Mice were acclimated at least one week prior to experimentation and were housed in standard environmental conditions with corn-cob bedding in groups of four. A standard pellet diet and water $a b$ libitum was provided. All murine experiments were performed between 8 AM and 1 PM.

\section{Polymicrobial sepsis and endotoxemia models}

Mice were subjected to cecal ligation and puncture (CLP) to induce polymicrobial sepsis, as previously described [7, 13]. During surgeries, mice were anesthetized with $2 \%$ isoflurane in oxygen, shaved over the abdominal area, disinfected with povidone-iodine, and placed supine on a heating pad. Following a $1-2 \mathrm{~cm}$ midline laparotomy incision, $66 \%$ of the cecum was ligated with a 4-0 silk tie (Syneture, Norwalk, CT). A through-and-through puncture was made on the anti-mesenteric side with a 22-gauge needle and a small amount of feces was extruded through the puncture holes to ensure perforation. The cecum was replaced in its original location, and the midline incision was closed in two layers with 4-0 silk. Following CLP, mice were resuscitated with $1 \mathrm{~mL}$ sterile normal saline (NS), (Hospira, Lake Forest, IL, USA) injected subdermally, 


\section{\begin{tabular}{ll} 
Cellular Physiology & Cell Physiol Biochem 2019;52:565-579 \\
\hline DOl: 10.33594/000000040 & 2019 The Author(s). Published by \\
\cline { 2 - 3 }
\end{tabular}

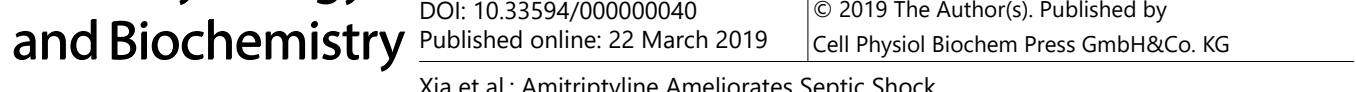

and placed on a heating pad for one hour. Sham mice underwent the above process except for ligation and puncture.

Endotoxemia was induced as previously described [8] through a $1 \mathrm{mg}$ intraperitoneal (IP) injection of lipopolysaccharide (LPS), which was derived from Escherichia coli 0111:B4 strain (Sigma-Aldrich, St. Louis, MO) and solubilized in NS (Hospira).

Amitriptyline treatment

At the time of CLP or LPS challenge, mice were randomized to IP delivery of 0.9\% NS (Hospira, Lake Forest, IL) or $16 \mathrm{mg} / \mathrm{kg}$ AT (Sigma-Aldrich) solubilized in NS, as previously described by Peng et al. [9].

\section{IL-10 treatment}

To evaluate the role of IL-10 during the early phase of sepsis, mice were randomized to intraperitoneal delivery of NS or 500 ng recombinant murine IL-10 (BioLegend, San Diego, CA) solubilized in NS at the time of CLP.

\section{Cytokine analysis}

Whole blood was harvested by cardiac puncture, collected in serum separator tubes (BD Biosciences, San Jose, CA), and centrifuged at $10,000 \mathrm{x}$ g for 10 minutes at $20^{\circ} \mathrm{C}$. Peritoneal fluid was harvested by peritoneal lavage and centrifuged at $450 \mathrm{xg}$ for $10 \mathrm{~min}$ at $9^{\circ} \mathrm{C}$. The serum and cell-free peritoneal fluid were stored in sterile tubes and frozen at $-80^{\circ} \mathrm{C}$ until cytokine analysis. The IL-6, IL-10, KC and MCP-1 concentrations in the samples were analyzed by cytometric bead array (BD Biosciences), as previously described [14].

\section{Bacterial counts}

Whole blood and peritoneal fluid were harvested as previously described $[15,16]$ using cardiac puncture and peritoneal lavage, respectively. Aerobic samples were serially diluted in sterile PBS and cultured on Tryptic Soy Agar plates (BD Biosciences). The plates were incubated at $37^{\circ} \mathrm{C}$ for 24 hours, after which colony counts were performed.

\section{Lung histology}

Mice were sacrificed sixteen hours after CLP. Lungs were inflated with $1 \mathrm{~mL} 10 \%$ formalin, harvested and fixed in $10 \%$ formalin for 48 hours, dehydrated in $70 \%$ ethanol for 72 hours and embedded in paraffin. 5-10 $\mu \mathrm{m}$ thick sections were prepared and stained with hematoxylin and eosin. Samples were viewed and graded with a $20 \mathrm{x}$ light microscopy magnification by a blinded investigator. A pathology grading system with a numerical score was adopted from previous definitions and evaluated alveolar edema (0-3) and leukocyte infiltration (0-4) [17].

\section{Bronchoalveolar lavage protein assay}

Bronchoalveolar lavage (BAL) of NS and AT-treated mice were obtained by instillation of NS through the trachea with a 20-gauge catheter, followed by removal of $2 \mathrm{ml}$ fluid. Protein concentration was determined using the BCA Protein Assay kit (Thermo Scientific, Waltham, MA). Absorbance was read at $562 \mathrm{~nm}$ using the ELx800 Microplate Reader (BioTek Instruments, Winooski, VT). A standard curve of BSA dilutions with known concentrations was used to calculate the protein concentrations of the samples.

Flow cytometry and PhosFlow analysis

Peritoneal cells were harvested by peritoneal lavage and centrifuged at $450 \mathrm{xg}$ for $10 \mathrm{~min}$. The pelleted cells enumerated with a cell counter (Beckman Coulter, Brea, CA), and analyses of cell surface antigen and intracellular cytokine expression were performed.

To analyze intracellular IL-10 expression in vivo, mice were pre-treated with protein transport inhibitor brefeldin A (BFA, BioLegend) as previously described [18]. $250 \mu \mathrm{g}$ of BFA were administered IP 30 min prior to challenge with LPS and administration of NS or $16 \mathrm{mg} / \mathrm{kg}$ AT. Peritoneal macrophages were isolated $90 \mathrm{~min}$ after LPS injection by peritoneal lavage and intracellular staining was performed as previously described [19]. 


\section{Cellular Physiology Cell Physiol Biochem 2019;52:565-579

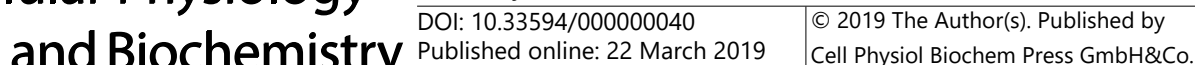 \\ Xia et al.: Amitriptyline Ameliorates Septic Shock}

To evaluate macrophage IL-10 generation in vitro, peritoneal cells were obtained by lavage from healthy mice. $100 \mathrm{ng} / \mathrm{mL}$ LPS was administered along with $2 \mu \mathrm{M}$ protein transport inhibitor monensin (MilliporeSigma, Darmstadt, Germany) and $100 \mu \mathrm{M}$ AT or $10 \mu \mathrm{M}$ ceramide (Avanti Polar Lipids, Alabaster, AL) or $20 \mu \mathrm{M}$ p38 kinase inhibitor SB239063 as indicated. Intracellular IL-10 levels were assessed 3 hours later as previously described [19].

To determine phosphorylated p38, macrophages were incubated with $100 \mathrm{ng} / \mathrm{mL}$ LPS for 30 minutes and subsequently fixed by addition of $90 \%$ methanol.

The following antibodies were used for flow cytometry analysis: Ly6G (Clone: 1A8, BD Biosciences), Ly6C (Clone: AL-21, BD Biosciences), CD11b (Clone: M1/70, BD Biosciences), F4/80 (Clone: T45-2342, BD Biosciences), IL-10 (Clone: JES5-16E3, BioLegend) and phospho-p38 (Clone: pT180/pY182, BD Biosciences). Flow cytometry acquisition and analysis were performed on an Attune Flow Cytometer (Life Technologies, Foster City, CA).

\section{Chemotaxis assay}

Bone marrow cells were harvested from femur and tibia in HBSS (ThermoFisher Scientific, Waltham, MA), centrifuged at $450 \mathrm{xg}$ and counted on a cell counter (Beckman Coulter, Brea, CA). 2 million cells were seeded on a transwell insert with $3 \mu \mathrm{m}$ pores (ThermoFisher Scientific). $100 \mathrm{ng} \mathrm{KC}$ were added to the bottom well and cells were incubated for $3 \mathrm{~h}$ at $37^{\circ} \mathrm{C}$. Non-migrated cells from the transwell insert and migrated cells from the bottom well were recovered and analyzed by flow cytometry.

\section{Statistics}

GraphPad Prism 6.0 (Graphpad Software, La Jolla, CA) was used to perform statistical comparisons. A two-tailed Student's t-test was used for two groups, or one-way ANOVA with Tukey post-hoc analysis were used for more than two groups. Kaplan-Meier method was used to calculate survival distributions, which were then compared using log-rank test.

\section{Results}

Amitriptyline treated septic mice demonstrate improved survival and decreased occurrence of hypothermia

Administration of AT at the time of CLP increased survival of septic mice compared to control mice (Fig. 1A, p = 0.03). Endotoxemic mice show rapid mortality within $24 \mathrm{~h}$ after the LPS challenge, which was also significantly ameliorated by AT administration (data not shown). Systemic IL-6 levels did not differ between treated and control mice six hours after CLP (Fig. 1B). Survival differences first became apparent sixteen hours after CLP. At this time, AT-treated septic mice were less hypothermic than control mice (Fig. $1 \mathrm{C},-2.06 \pm 0.46{ }^{\circ} \mathrm{C}$ $\mathrm{CLP}+\mathrm{NS}$ vs $-0.88 \pm 0.43^{\circ} \mathrm{C} \mathrm{CLP}+\mathrm{AT}, \mathrm{p}=0.03$ ). There were no differences in local and systemic bacterial burden at this time (Fig. 1D), nor at an earlier time-point four hours after CLP (data not shown).

\section{Amitriptyline treatment mitigates pulmonary injury during sepsis}

AT treatment has previously been reported to ameliorate lung injury during $S$. aureus infection [9]. Here, we assessed lung pathology in our polymicrobial sepsis model. Tissues were harvested $16 \mathrm{~h}$ after CLP. Lung edema and polymorphonuclear leukocyte infiltration was ameliorated in AT-treated septic mice, compared to sham and NS-treated septic mice (Fig. 2A+B). In line with these observations, AT-treated septic mice also had reduced protein concentrations in BAL $3 \mathrm{~h}$ after CLP (Fig. 2C, $0.79 \pm 0.24 \mathrm{mg} / \mathrm{mL}$ CLP+NS vs $0.19 \pm 0.02 \mathrm{mg} /$ $\mathrm{mL} C L P+A T, p=0.03)$. 


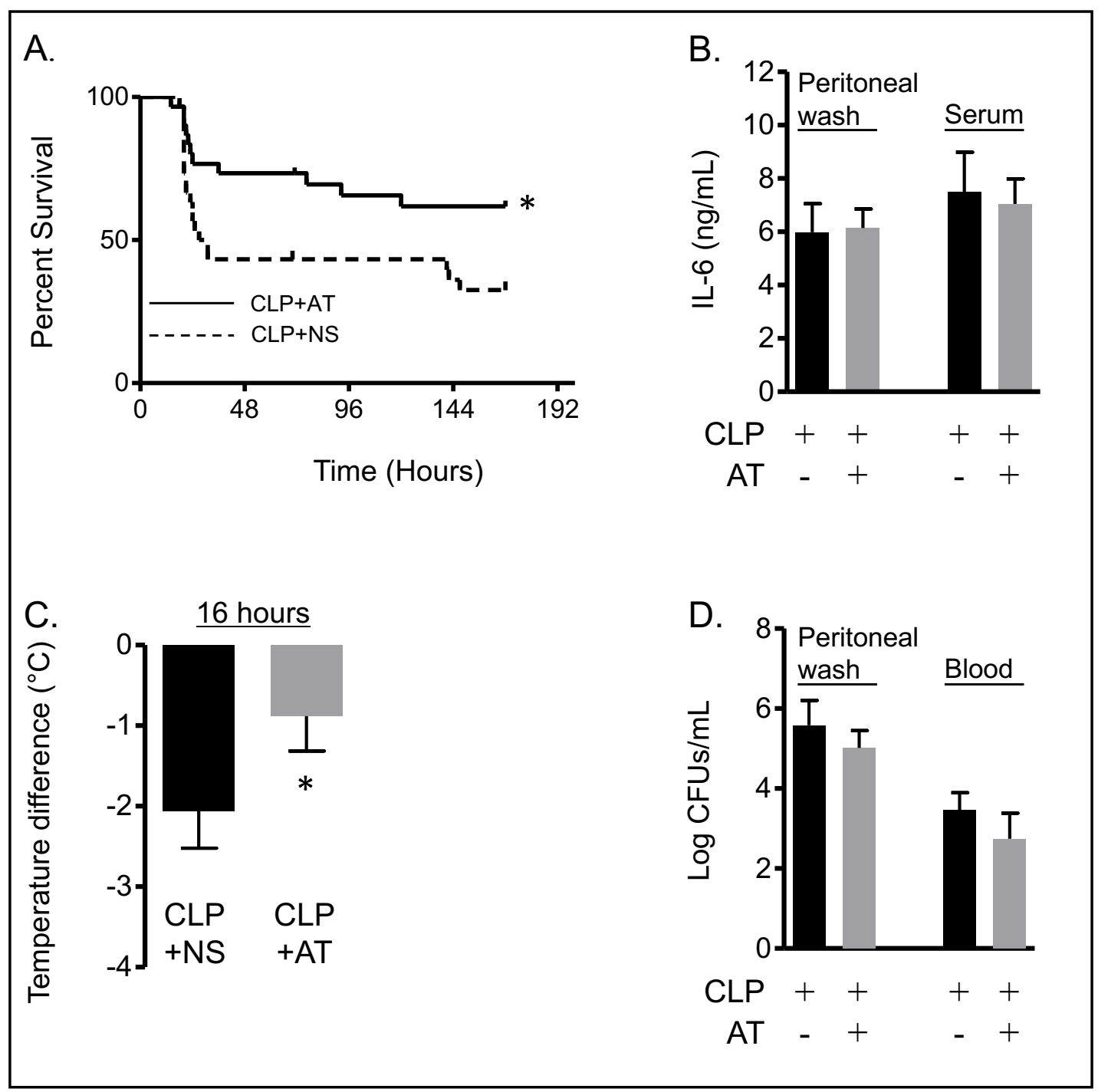

Fig. 1. Amitriptyline treated septic mice demonstrate improved survival and decreased hypothermia, despite no differences in local and systemic IL-6 levels and bacterial burden. Mice underwent CLP. A) Control and AT-treated mice were monitored for survival. * $\mathrm{p}<0.05$ vs CLP+NS; $\mathrm{n}=30$ mice/group. B) Peritoneal wash and blood samples were collected 6 hours after CLP for cytokine analysis, and IL- 6 was quantified for NS- and AT-treated septic mice. $n=10$ mice/group. C) Aural temperatures of septic mice treated with NS or AT are shown 16 h after CLP. * $\mathrm{p}<0.05$ vs CLP+NS; $\mathrm{n}=25$ mice/group. D) Peritoneal wash and blood were collected 16 hours after CLP and samples were cultured to determine bacterial burden. $\mathrm{n}=6$ mice/group.

\section{Leukocyte chemoattractant levels and accumulation are decreased with AT treatment}

The observed differences in leukocyte recruitment to the lung prompted us to also examine the recruitment of neutrophils and monocytes to the site of the septic insult - the peritoneal cavity. We analyzed leukocyte recruitment to the peritoneum $3 \mathrm{~h}$ after CLP and observed a 1.7-fold decrease in peritoneal neutrophil accumulation in AT-treated septic mice compared to NS saline treated mice (Fig. 3A, $2.26 \pm 0.48 \times 10^{6}$ cells $/ \mathrm{mL}$ CLP+NS vs $1.31 \pm$ $0.23 \times 10^{6}$ cells $/ \mathrm{mL} \mathrm{CLP}+\mathrm{AT}, \mathrm{p}=0.04$ ). This coincided with a 1.4-fold decrease in serum KC in the AT-treated group (Fig. 3B, $1.90 \pm 0.13 \mathrm{ng} / \mathrm{mL}$ CLP+NS vs $1.37 \pm 0.17 \mathrm{ng} / \mathrm{mL} \mathrm{CLP}+\mathrm{AT}, \mathrm{p}=$ 0.02 ). In an in vitro assay, we also tested whether AT influences chemotaxis of neutrophils directly. AT treatment decreased neutrophil chemotaxis towards KC 2.4-fold (Fig. 3C, 55.38 $\pm 12.45 \%$ CLP+NS vs. $22.98 \pm 13.59 \%$ CLP+AT, $p=0.0005)$. Similarly, a 1.9 -fold decrease in peritoneal monocyte accumulation (Fig. 3D, $1.00 \pm 0.11 \times 10^{6}$ cells/mL CLP+NS vs $0.52 \pm$ 


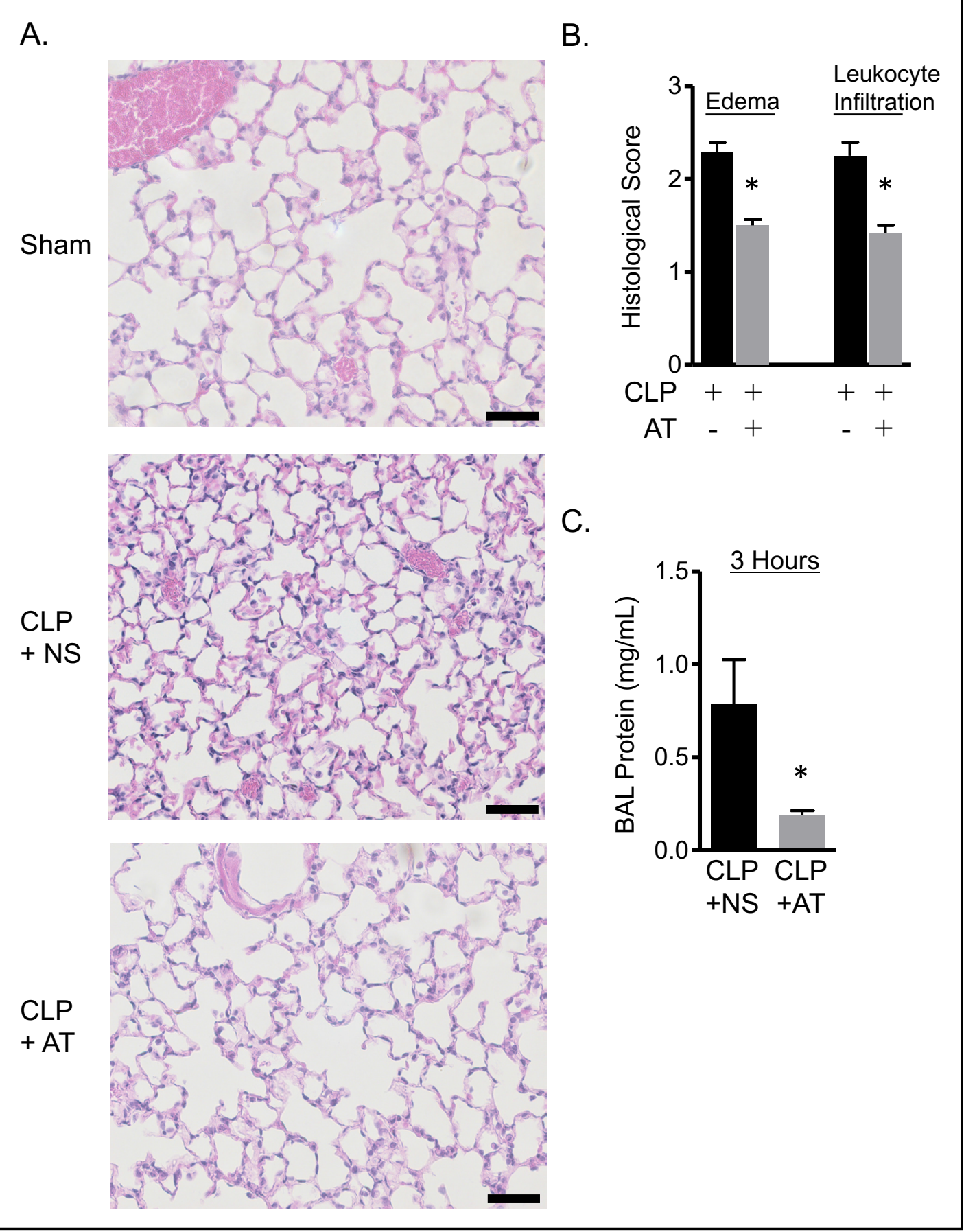

Fig. 2. Amitriptyline treatment mitigates pulmonary injury during sepsis. Lungs from sham and septic mice were collected 16 hours after CLP. A) Samples were embedded in paraffin, stained with hematoxylin and eosin, and sectioned. B) Edema and leukocyte infiltration histology scores were compared between septic control and AT-treated mice. ${ }^{*} \mathrm{p}<0.05$ vs CLP+NS; $\mathrm{n}=6$ mice/group. $\mathrm{C}$ ) BAL fluid was collected and protein concentration was determined. ${ }^{*} \mathrm{p}<0.05$ vs $\mathrm{CLP}+\mathrm{NS} ; \mathrm{n}=6$ mice/group.

$0.11 \times 10^{6}$ cells $/ \mathrm{mL}$ CLP+AT, $\mathrm{p}<0.01$ ) and a 3 -fold decrease in serum MCP-1 levels (Fig. 3E, $4.13 \pm 0.97 \mathrm{ng} / \mathrm{mL} \mathrm{CLP}+\mathrm{NS}$ vs $1.32 \pm 0.37 \mathrm{ng} / \mathrm{mL} \mathrm{CLP}+\mathrm{AT}, \mathrm{p}=0.02$ ) was observed with ATtreatment. Serum KC and MCP-1 levels in sham mice were below the detection limit (data not shown). 
A.

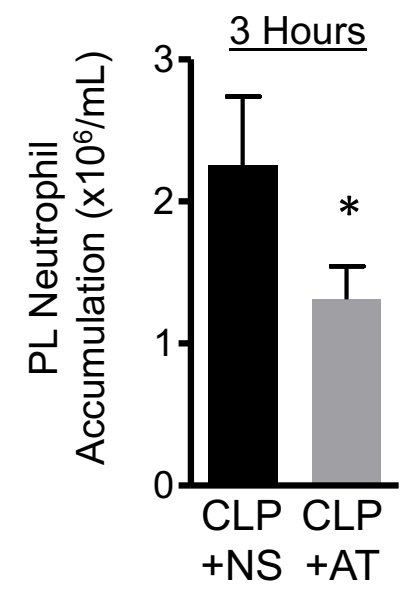

D.

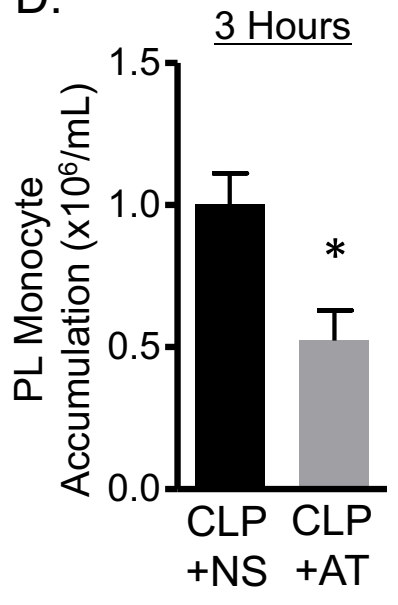

B.

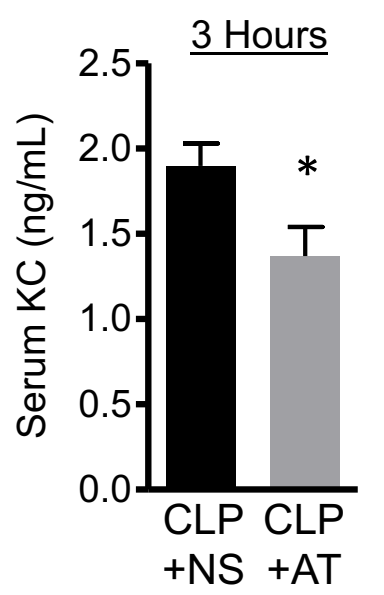

E.

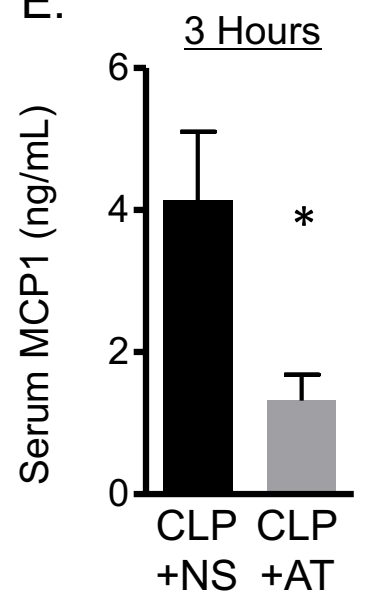

C. in vitro

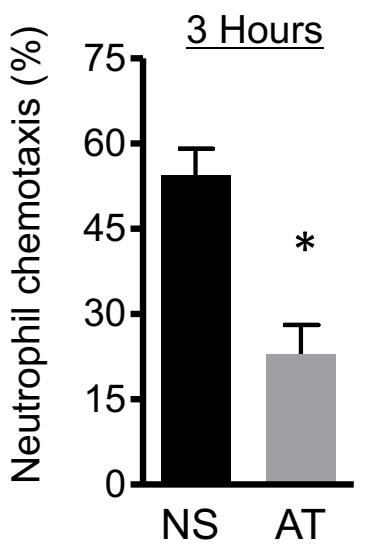

Fig. 3. Leukocyte chemoattractant levels and accumulation are decreased with AT treatment. Peritoneal lavage (PL) and blood were collected for cellular and cytokine analysis, respectively. A) Neutrophil accumulation and $\mathrm{B}$ ) serum $\mathrm{KC}$ levels were determined for septic control and AT-treated mice three hours after CLP. * $\mathrm{p}<0.05$ vs CLP+NS; $\mathrm{n}=8$ mice/group. C) Neutrophil chemotaxis toward KC was determined in an in vitro transwell assay and analyzed by flow cytometry. ${ }^{*} \mathrm{p}<0.05$ vs NS; $n=8$ replicates in 2 independent experiments. D) Monocyte accumulation and E) serum MCP-1 levels were determined for septic control and AT-treated mice three hours after CLP. ${ }^{*} \mathrm{p}<0.05$ vs CLP+NS; $\mathrm{n}=8$ mice/group.

IL-10 production is increased in septic AT-treated mice and exogenous IL-10 administration reiterates the amelioration of the host response seen with AT treatment

Due to suppressed leukocyte accumulation and unchanged IL-6 levels in AT-treated septic mice compared to septic control mice, we investigated the role of anti-inflammatory IL-10. AT-treatment caused a 2.7-fold increase in peritoneal IL-10 concentration in septic mice 6 hours after CLP (Fig. 4A, $26.50 \pm 4.92 \mathrm{pg} / \mathrm{mL}$ CLP+NS vs $72.20 \pm 21.16 \mathrm{pg} / \mathrm{mL} \mathrm{CLP+AT}$, $p=0.04$ ). To establish the role of IL-10 in the response of AT-treated mice to sepsis, mice were treated with exogenous IL-10 at the time of CLP. Similar to AT-treatment, administration of IL-10 reduced hypothermia in septic mice (Fig. $4 \mathrm{~B},-4.63 \pm 0.81^{\circ} \mathrm{C} C L P+N S$ vs $-1.69 \pm 0.52^{\circ} \mathrm{C}$ $\mathrm{CLP}+\mathrm{IL}-10, \mathrm{p}=0.01$ ). Treatment with IL-10 also decreased peritoneal KC levels (Fig. 4C, 2.75 $\pm 0.20 \mathrm{ng} / \mathrm{mL}$ CLP+NS vs $1.99 \pm 0.20 \mathrm{ng} / \mathrm{mL} \mathrm{CLP}+\mathrm{IL}-10, \mathrm{p}=0.02$ ) and neutrophil accumulation 
A.

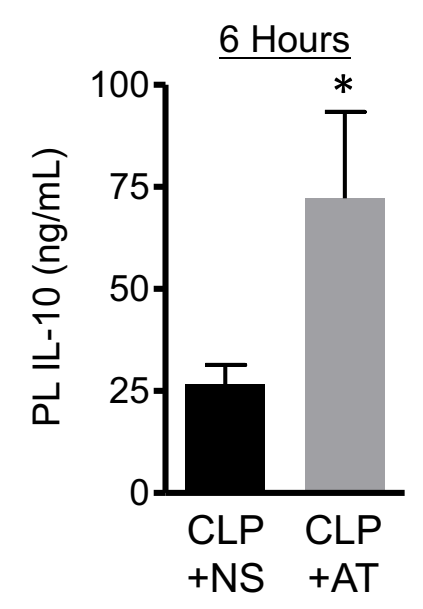

D.

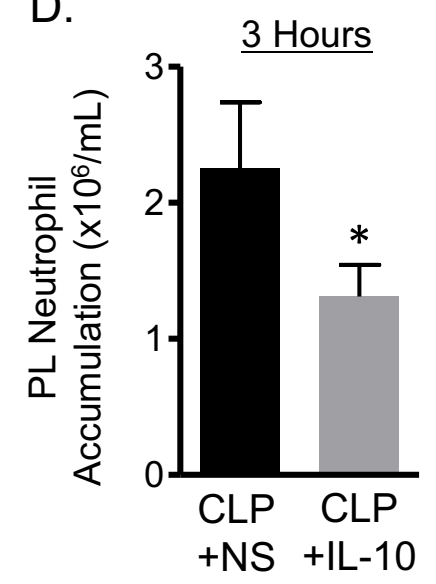

B.

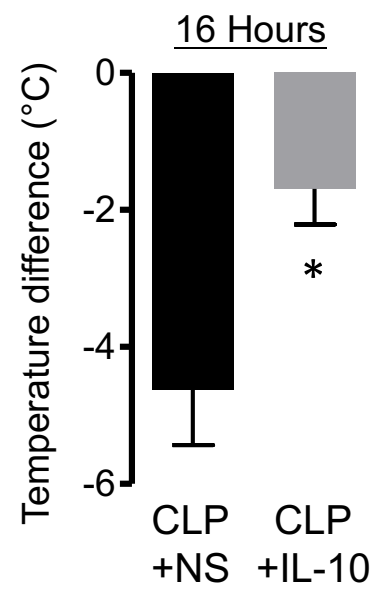

C.

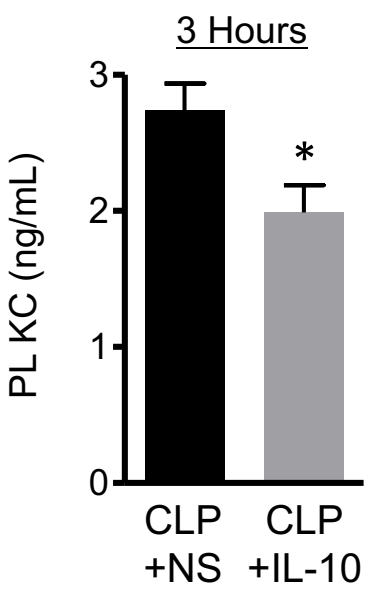

E.

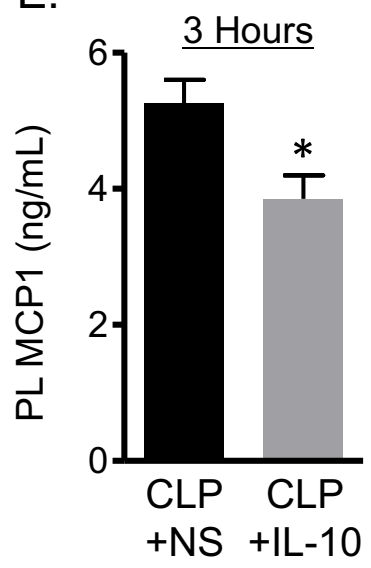

Fig. 4. IL-10 production is increased in septic AT-treated mice and exogenous IL-10 administration reiterates the amelioration of septic shock and leukocyte response seen with AT treatment. A) IL-10 levels were quantified from peritoneal lavage (PL) six hours after CLP; ${ }^{*} \mathrm{p}<0.05$ vs CLP+NS; $\mathrm{n}=10$ mice/group. B) Mice were randomized to intraperitoneal delivery of NS or $500 \mathrm{ng}$ recombinant murine IL-10 at the time of CLP. Aural temperature was determined 16 hours post-CLP. ${ }^{*} \mathrm{p}<0.05$ vs CLP+NS; $\mathrm{n}=8$ mice/group. PL and blood were collected for cellular and cytokine analysis, respectively. C) Serum KC levels and D) local neutrophil accumulation were determined for septic control and IL-10-treated mice three hours after CLP. * $\mathrm{p}<0.05$ vs CLP+NS; $\mathrm{n}=16$ mice/group. E) Serum MCP-1 levels were determined for septic control and IL10 -treated mice three hours after CLP. ${ }^{*} \mathrm{p}<0.05$ vs CLP+NS; $\mathrm{n}=16$ mice/group.

(Fig. $4 \mathrm{D}, 2.59 \pm 0.35 \times 10^{6}$ cells $/ \mathrm{mL}$ CLP+NS vs. $1.82 \pm 0.21 \times 10^{6}$ cells $/ \mathrm{mL} \mathrm{CLP+IL-10,} \mathrm{p}=0.03$ ) 3 hours after CLP. Peritoneal MCP-1 levels were also reduced in the IL-10 treated group (Fig. $4 \mathrm{E}, 5.25 \pm 0.35 \mathrm{ng} / \mathrm{mL} \mathrm{CLP}+\mathrm{NS}$ vs $3.85 \pm 0.34 \mathrm{ng} / \mathrm{mL}$ CLP+IL-10, $\mathrm{p}<0.01)$, but monocyte recruitment was not significantly changed (data not shown).

Peritoneal macrophage IL-10 production is increased in AT-treated septic mice

In order to confirm the increase in IL-10 production seen in CLP mice upon AT treatment in another model of sepsis, we tested the IL-10 response of endotoxemic mice 90 min after the LPS challenge. AT treatment of endotoxemic mice increased serum IL-10 levels 10-fold compared to the control group (Fig. $5 \mathrm{~A}, 0.32 \pm 0.06 \mathrm{ng} / \mathrm{mL}$ LPS+NS vs $3.14 \pm 0.33 \mathrm{ng} / \mathrm{mL}$ LPS+AT, $\mathrm{p}<0.01$ ). 


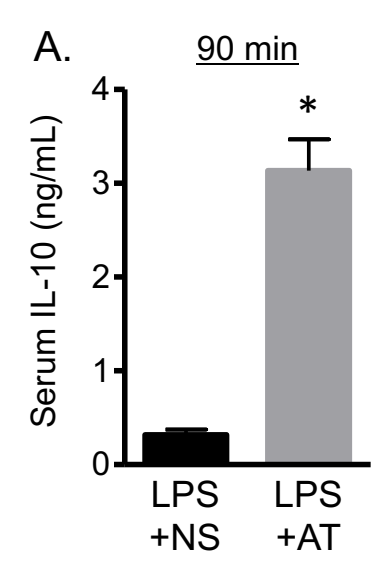

B.

C.

D.

$\underline{\text { in vivo }}$

$\underline{\text { R1 Gate }}$

$\underline{\text { R2 Gate }}$
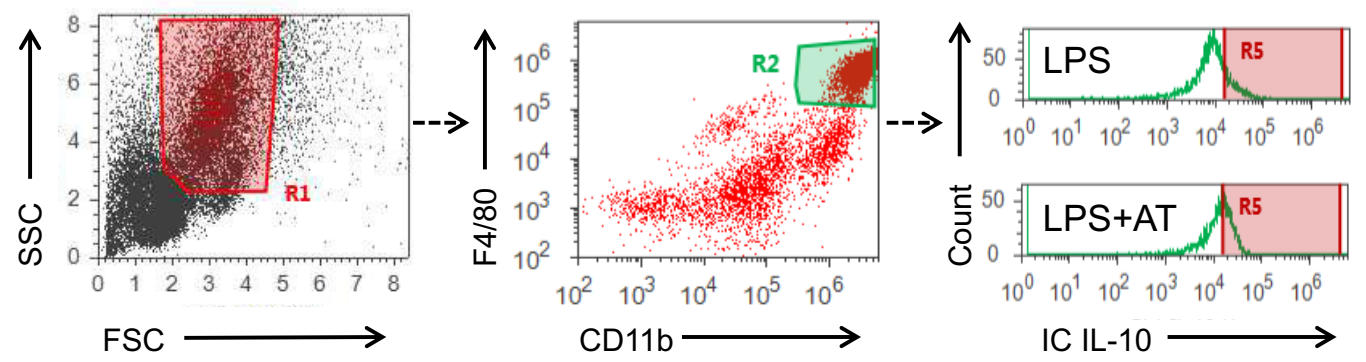

E.

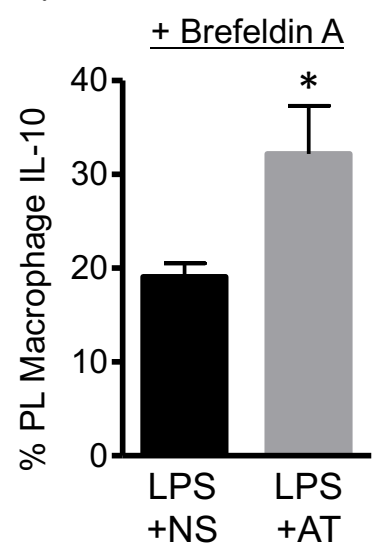

Fig. 5. Macrophages are the predominant source of IL-10 production in AT-treated septic mice. A) IL-10 levels were quantified from blood 90 minutes after LPS challenge; *, $\mathrm{p}<0.05$ vs LPS+NS; $\mathrm{n}=8$ mice/group. B-E) Mice were treated with protein transport inhibitor Brefeldin A, challenged with LPS and treated with either NS or AT in vivo. Peritoneal leukocytes were isolated and analyzed by flow cytometry for intracellular IL-10 content. Macrophages were gated based on CD11b and F4/80 expression. * $\mathrm{p}<0.05$ vs LPS+NS; $n=4$ mice/group.

We next sought to determine which cells produce IL-10 in an AT-mediated manner. In order to stop cytokine secretion and thus enable intracellular detection, we pre-treated mice with the protein transport inhibitor brefeldin A. This was followed by LPS challenge and treatment with NS or AT. Ninety minutes later, peritoneal cells were isolated and analyzed by 
A.
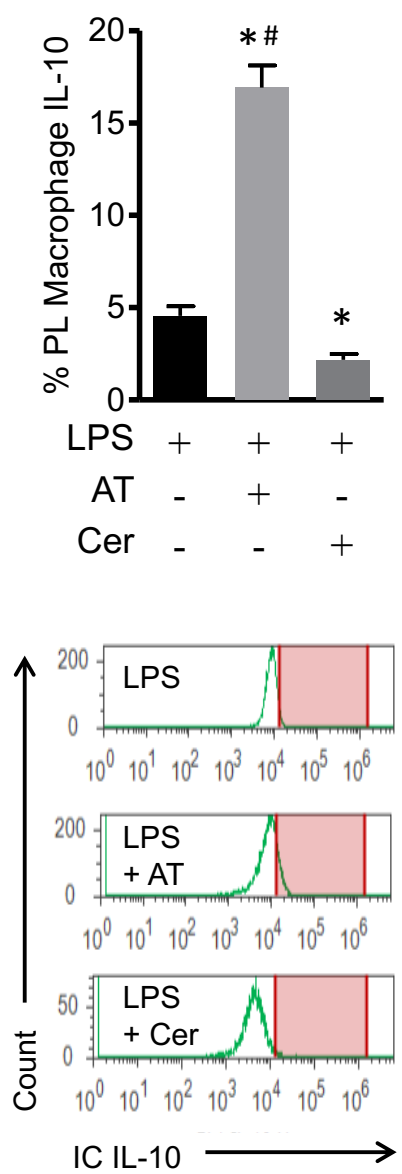

B.
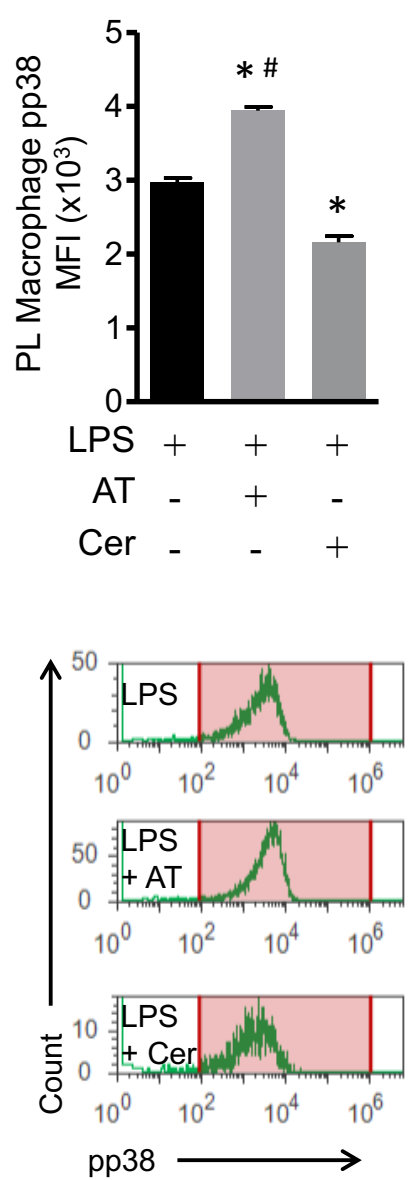

C.
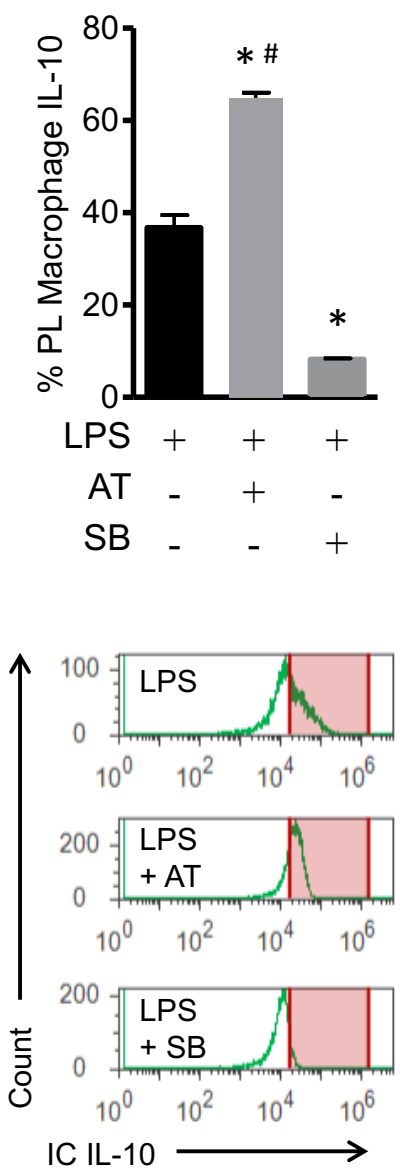

Fig. 6. Ceramide regulates peritoneal macrophage IL-10 production through p38 signaling. Peritoneal lavage (PL) macrophages were pre-treated with either AT or ceramide and stimulated with LPS. A) The percentage of IL-10 producing macrophages was quantified. * $\mathrm{p}<0.05$ vs + LPS; \# $\mathrm{p}<0.05$ vs + LPS+Cer; $\mathrm{n}=4-8$ mice/ group, as well as B) phospho-p38 levels in macrophages. ${ }^{*} \mathrm{p}<0.05$ vs + LPS; \# $<<0.05$ vs + LPS + Cer; $n=4$ mice/group. C) The percentage of IL-10 producing macrophages was measured and compared when treated with AT compared to LPS alone or LPS and selective p38 inhibitor SB239063. * p <0.05 vs +LPS; \# p<0.05 vs $+\mathrm{LPS}+\mathrm{SB} ; \mathrm{n}=4$ mice/group. The gating strategy is the same as shown in Fig. 5. One representative histogram per group is shown.

flow cytometry. Peritoneal macrophages were found to produce IL-10 in an AT-driven fashion (Fig. 5B-E). Specifically, there was a 1.7-fold increase in intracellular IL-10 expression in macrophages from endotoxemic mice that received AT over endotoxemic mice that received NS (Fig. 5E, $19.08 \pm 1.42 \%$ LPS+NS vs $32.20 \pm 5.12 \%$ LPS+AT, p <0.01).

\section{Ceramide regulates peritoneal macrophage IL-10 production through p38 signaling}

We next investigated potential pathways through which AT could drive macrophage IL10 production. AT affects a number of different targets, including the ceramide-generating enzyme Asm. We first established that the in vitro treatment of peritoneal macrophages with AT increased IL-10 production on a per cell basis. Ceramide, on the other hand, reduced IL-10 production (Fig. $6 \mathrm{~A}, 4.56 \pm 0.52 \%+$ LPS vs $16.92 \pm 1.20 \%+$ LPS + AT vs $2.17 \pm 0.33 \%$ + LPS+Ceramide, $\mathrm{p}<0.01$ ). 
The p38 mitogen-activated kinase (MAPK) has previously been shown to be required for IL-10 production [20, 21]. To determine whether AT exerts its effects on IL-10 production through the p38-MAPK pathway, we analyzed p38 phosphorylation in LPSchallenged macrophages treated with AT or ceramide. Thirty minutes after LPS challenge, p38 phosphorylation was significantly increased in AT-treated cells and significantly decreased in ceramide-treated cells compared to LPS stimulation alone (Fig. 6B, $2.97 \pm$ $0.06 \times 10^{3}$ MFI LPS vs $3.94 \pm 0.05 \times 10^{3}$ MFI LPS+AT vs $2.16 \pm 0.08 \times 10^{3}$ MFI LPS+Ceramide, $\mathrm{p}<0.01$ ). Similarly, macrophage IL-10 production in response to LPS was increased upon AT treatment, but decreased upon treatment with the selective p38 inhibitor SB239063 (Fig. 6C, $36.80 \pm 2.70 \%$ LPS vs $64.93 \pm 1.12 \%$ LPS + AT vs $8.22 \pm 0.24 \%$ LPS+SB, $p<0.01$ ). Thus, AT treatment increased IL-10 generation and p38 phosphorylation, while inhibition of the p38 pathway decreased IL-10 production. We postulate that this is mediated through inhibition of ceramide generation, however, further studies are necessary to support this.

\section{Discussion}

We previously observed that AT treatment mitigates sepsis-induced tumor necrosis factor expression and coagulopathy [8]. In this study, we aimed to identify further antiinflammatory properties or protective effects of AT in sepsis. First, we observed that AT ameliorated septic shock, as demonstrated by improved hypothermia in AT-treated septic mice and increased survival compared to controls. Neither bacterial burden nor systemic IL- 6 levels were changed. Secondly, AT-treated septic mice also had decreased pulmonary edema and reduced leukocyte accumulation in the lungs and peritoneum. This can be explained by the observed decrease of myeloid cell chemoattractants upon AT treatment. Finally, AT also directly impaired neutrophil chemotaxis at the cellular level.

The ameliorative effects of AT appear to be driven by IL-10 production. The administration of AT increases IL-10 production in both septic and endotoxemic mice, and the administration of exogenous IL-10 recapitulates the cellular changes seen with AT treatment in septic mice. Previous publications also showed a survival advantage in septic mice treated with human recombinant IL-10 when given $5 \mathrm{~h}$ or $6 \mathrm{~h}$ after CLP $[22,23]$ and extended the therapeutic window when combined with rescue surgery at 30h after CLP [24]. We show that peritoneal macrophages are the predominant source of AT-mediated IL-10 production. Our further in vitro studies indicate a p38-dependent mechanism: ceramide inhibits p38 phosphorylation and thus activation, whereas AT, possibly through the functional inhibition of the ceramidegenerating enzyme acid sphingomyelinase (Asm), enhances p38 phosphorylation upon LPS stimulation. In line with previous reports, IL-10 production greatly depended on p38 activity, as it was markedly reduced upon addition of a specific p38 inhibitor [20,21].

Although IL-10 levels were increased in AT-treated septic mice, it is important to note that AT treatment did not cause a state of general immunosuppression, as local and systemic bacterial burden at 4 and 16 hours, and systemic IL- 6 levels 6 hours after CLP were similar in AT-treated and control mice. Thus, AT treatment only tempered the innate immune response, but did not lead to broad immunosuppression.

In line with this, the survival advantage of AT-treated mice was evident at 16-20 hours after CLP and their survival curve plateaued shortly after. In contrast, the mortality of septic control mice still increased at late time-points ( $>144$ hours). These delayed deaths may reflect a "second-hit" due to an unresolved infection in mice that survived the initial hyperinflammatory response [25]. Previous reports from animal models and patients indicate that the delayed, compensatory increase in anti-inflammatory mediators may be mitigated by blocking the initial inflammatory response $[26,27]$. Consistent with this, the amelioration of the initial inflammatory response through administration of AT avoided the second-hit phenomenon in AT-treated septic mice. 
Another clinically promising finding is that AT-treatment mitigated pulmonary injury in septic mice, as defined by edema and leukocyte infiltration and BAL protein concentrations. These results are complemented by several prior studies. For example, ceramide accumulation in bronchial epithelial cells has previously been shown to increase pulmonary infection susceptibility in cystic fibrosis patients and murine models [28-30]. Reducing pulmonary ceramide levels through AT treatment or the use of other Asm inhibitors was shown to decrease infection-susceptibility to P. aeruginosa [28, 30]. Reduction of Asm activity also decreased pulmonary inflammation in cystic fibrosis mice even prior to infection, consistent with the present finding of an anti-inflammatory effect of AT treatment. Additionally, genetic and pharmacological Asm activity reduction was reported to protect mice from lung edema during S. aureus sepsis [9]. Mechanistically, Peng et al. demonstrated that accumulation of ceramide due to increased Asm activity promoted superoxide formation in endothelial cells, which induced degradation of tight junction proteins and resulted in leakiness of the pulmonary endothelial barrier [9]. Peng et al. pre-treated mice with AT for several days before inducing sepsis [9]. Our study shows immunomodulatory effects and protection from septic shock with a single loading dose of AT, which is more relevant clinically. Additionally, the fast onset of effects of a single dose of AT reported here highlight its potential to attenuate the initial hyper-inflammatory response and thus prevent the second-hit phenomenon as described above.

AT can regulate a number of targets, including serotonin transporters, histamine and muscarinic acetylcholine receptors, ion channels and sphingolipid-metabolizing enzymes such as Asm [31]. Asm inhibition with AT has been previously shown to mediate antiinflammatory effects through reduction of ceramide levels [30]. Reduction of Asm activity has also been previously implicated in the regulation of p38 activation in the central nervous system [12, 32, 33] and in cardiac ischemic-reperfusion injury [34]. We observed that ceramide had opposing effects to AT on IL-10 production and p38 phosphorylation in our in vitro studies, suggesting that these effects of AT may be due to the drug's effects on sphingolipids. However, further studies are necessary to support this conclusion.

It is estimated that approximately one-third of trauma patients over the age of 45 years take a neuropsychiatric medication [33]. AT is a common drug with well-established dosing and safety profiles, used to treat mental illnesses such as depression and anxiety. It is also used off-label for migraines, irritable bowel syndrome and fibromyalgia [35-39]. Despite the prevalence of AT in the United States, a national database examining AT usage among trauma/septic patients and its association with hospital outcomes and survival is lacking. This information, however, would help to tailor AT as an appropriate therapy. A healthy eighteen-year-old trauma patient's septic course will not be identical to that of an elderly immunosuppressed patient with multiple comorbidities. To effectively treat a heterogeneous patient population with a timeline sensitive illness and tailor appropriate immune-modulating therapies, we need to more effectively stage sepsis and determine the immune status and functional deficits of the critically ill patient [40].

\section{Conclusion}

Altogether, AT treatment improved survival in septic shock and increased peritoneal macrophage IL-10 production through p38 activation, mitigating an initial overwhelming inflammatory burden. This resulted in a checked inflammatory milieu and controlled leukocyte response. Therefore, we propose that AT treatment is a promising therapeutic approach in septic shock. Future focus on staging sepsis to determine patients who would benefit the most from AT treatment is needed. 


\section{Cellular Physiology Cell Physiol Biochem 2019;52:565-579

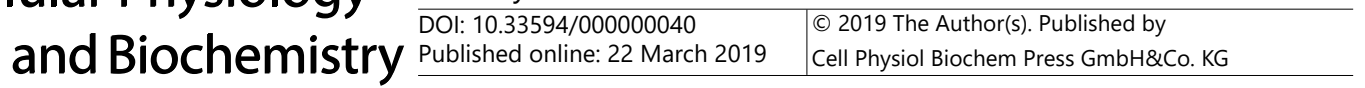 \\ Xia et al.: Amitriptyline Ameliorates Septic Shock}

\section{Acknowledgements}

BX, NB, LW, AP: Design of the work, data collection, data analysis and interpretation, drafting the article, critical revision of the article, and final approval of the version to be published. TP, VN, EG and CC: Conception of the work, data analysis and interpretation, drafting the article, critical revision of the article, and final approval of the version to be published. The authors would like to acknowledge H. Goetzman and L. England for excellent veterinarian and flow cytometrical support.

\section{Disclosure Statement}

The authors declare no conflicts of interest.

\section{References}

- 1 Rhodes A, Evans LE, Alhazzani W, Levy MM, Antonelli M, Ferrer R, Kumar A, Sevransky JE, Sprung CL, Nunnally ME, Rochwerg B, Rubenfeld GD, Angus DC, Annane D, Beale RJ, Bellinghan GJ, Bernard GR, Chiche JD, Coopersmith C, De Backer DP, et al.: Surviving Sepsis Campaign: International Guidelines for Management of Sepsis and Septic Shock: 2016. Crit Care Med 2017;45:486-552.

- 2 Gaieski DF, Mikkelsen ME, Band RA, Pines JM, Massone R, Furia FF, Shofer FS, Goyal M: Impact of time to antibiotics on survival in patients with severe sepsis or septic shock in whom early goal-directed therapy was initiated in the emergency department. Crit Care Med 2010;38:1045-1053.

- 3 Zubert S, Funk DJ, Kumar A: Antibiotics in sepsis and septic shock: like everything else in life, timing is everything. Crit Care Med 2010;38:1211-1212.

- 4 Gaieski DF, Edwards JM, Kallan MJ, Carr BG: Benchmarking the incidence and mortality of severe sepsis in the United States. Crit Care Med 2013;41:1167-1174.

- 5 Taniguchi T, Koido Y, Aiboshi J, Yamashita T, Suzaki S, Kurokawa A: Change in the ratio of interleukin-6 to interleukin-10 predicts a poor outcome in patients with systemic inflammatory response syndrome. Crit Care Med 1999;27:1262-1264.

6 Hotchkiss RS, Monneret G, Payen D: Immunosuppression in sepsis: a novel understanding of the disorder and a new therapeutic approach. Lancet Infect Dis 2013;13:260-268.

- 7 Johnson BL 3rd, Rice TC, Xia BT, Boone KI, Green EA, Gulbins E, Caldwell CC: Amitriptyline Usage Exacerbates the Immune Suppression Following Burn Injury. Shock 2016;46:541-548.

- 8 Xia BT, Beckmann N, Winer LK, Kim Y, Goetzman HS, Veile RE, Gulbins E, Goodman MD, Nomellini V, Caldwell CC: Amitriptyline Treatment Mitigates Sepsis-Induced Tumor Necrosis Factor Expression and Coagulopathy. Shock 2018; DOI:10.1097/shk.0000000000001146.

- 9 Peng H, Li C, Kadow S, Henry BD, Steinmann J, Becker KA, Riehle A, Beckmann N, Wilker B, Li PL, Pritts T, Edwards MJ, Zhang Y, Gulbins E, Grassme H: Acid sphingomyelinase inhibition protects mice from lung edema and lethal Staphylococcus aureus sepsis. J Mol Med (Berl) 2015;93:675-689.

- 10 Kubera M, Holan V, Mathison R, Maes M: The effect of repeated amitriptyline and desipramine administration on cytokine release in C57BL/6 mice. Psychoneuroendocrinology 2000;25:785-797.

- 11 Ma J, Gulbins E, Edwards MJ, Caldwell CC, Fraunholz M, Becker KA: Staphylococcus aureus alpha-Toxin Induces Inflammatory Cytokines via Lysosomal Acid Sphingomyelinase and Ceramides. Cell Physiol Biochem 2017;43:2170-2184.

12 Tai YH, Tsai RY, Lin SL, Yeh CC, Wang JJ, Tao PL, Wong CS: Amitriptyline suppresses neuroinflammationdependent interleukin-10-p38 mitogen-activated protein kinase-heme oxygenase-1 signaling pathway in chronic morphine-infused rats. Anesthesiology 2009;110:1379-1389.

- 13 Baker CC, Chaudry IH, Gaines HO, Baue AE: Evaluation of factors affecting mortality rate after sepsis in a murine cecal ligation and puncture model. Surgery 1983;94:331-335.

- 14 Rice TC, Seitz AP, Edwards MJ, Gulbins E, Caldwell CC: Frontline Science: Sphingosine rescues burn-injured mice from pulmonary Pseudomonas aeruginosa infection. J Leukoc Biol 2016;100:1233-1237. 


\section{Cellular Physiology Cell Physiol Biochem 2019;52:565-579 \begin{tabular}{c|c|c|c|}
\hline DOI: 10.33594/000000040 & (O) 2019 The Author(s). Published by \\
\hline
\end{tabular} and Biochemistry Published online: 22 March 2019 Cell Physiol Biochem Press GmbH\&Co. KG \\ Xia et al.: Amitriptyline Ameliorates Septic Shock}

15 Kasten KR, Prakash PS, Unsinger J, Goetzman HS, England LG, Cave CM, Seitz AP, Mazuski CN, Zhou TT, Morre M, Hotchkiss RS, Hildeman DA, Caldwell CC: Interleukin-7 (IL-7) treatment accelerates neutrophil recruitment through gamma delta T-cell IL-17 production in a murine model of sepsis. Infect Immun 2010;78:4714-4722.

- 16 Kuethe JW, Midura EF, Rice TC, Caldwell CC: Peritoneal wash contents used to predict mortality in a murine sepsis model. J Surg Res 2015;199:211-219.

- 17 Cimolai N, Taylor GP, Mah D, Morrison BJ: Definition and application of a histopathological scoring scheme for an animal model of acute Mycoplasma pneumoniae pulmonary infection. Microbiol Immunol 1992;36:465-478.

18 Liu F, Whitton JL: Cutting edge: re-evaluating the in vivo cytokine responses of CD8+ T cells during primary and secondary viral infections. J Immunol 2005;174:5936-5940.

19 Thiel M, Caldwell CC, Kreth S, Kuboki S, Chen P, Smith P, Ohta A, Lentsch AB, Lukashev D, Sitkovsky MV: Targeted deletion of HIF-1alpha gene in T cells prevents their inhibition in hypoxic inflamed tissues and improves septic mice survival. PLoS One 2007;2:e853.

20 Guo X, Gerl RE, Schrader JW: Defining the involvement of p38alpha MAPK in the production of anti- and proinflammatory cytokines using an SB 203580-resistant form of the kinase. J Biol Chem 2003;278:2223722242.

21 Ma W, Lim W, Gee K, Aucoin S, Nandan D, Kozlowski M, Diaz-Mitoma F, Kumar A: The p38 mitogen-activated kinase pathway regulates the human interleukin-10 promoter via the activation of Sp1 transcription factor in lipopolysaccharide-stimulated human macrophages. J Biol Chem 2001;276:13664-13674.

- 22 Kato T, Murata A, Ishida H, Toda H, Tanaka N, Hayashida H, Monden M, Matsuura N: Interleukin 10 reduces mortality from severe peritonitis in mice. Antimicrob Agents Chemother 1995;39:1336-1340.

23 Latifi SQ, O'Riordan MA, Levine AD: Interleukin-10 controls the onset of irreversible septic shock. Infect Immun 2002;70:4441-4446.

24 Manley MO, O’Riordan MA, Levine AD, Latifi SQ: Interleukin 10 extends the effectiveness of standard therapy during late sepsis with serum interleukin 6 levels predicting outcome. Shock 2005;23:521-526.

25 Bone RC: Toward a theory regarding the pathogenesis of the systemic inflammatory response syndrome: what we do and do not know about cytokine regulation. Crit Care Med 1996;24:163-172.

26 van der Poll T, Coyle SM, Kumar A, Barbosa K, Agosti JM, Lowry SF: Down-regulation of surface receptors for TNF and IL-1 on circulating monocytes and granulocytes during human endotoxemia: effect of neutralization of endotoxin-induced TNF activity by infusion of a recombinant dimeric TNF receptor. J Immunol 1997;158:1490-1497.

27 van der Poll T, Coyle SM, Levi M, Jansen PM, Dentener M, Barbosa K, Buurman WA, Hack CE, ten Cate JW, Agosti JM, Lowry SF: Effect of a recombinant dimeric tumor necrosis factor receptor on inflammatory responses to intravenous endotoxin in normal humans. Blood 1997;89:3727-3734.

28 Becker KA, Riethmuller J, Luth A, Doring G, Kleuser B, Gulbins E: Acid sphingomyelinase inhibitors normalize pulmonary ceramide and inflammation in cystic fibrosis. Am J Respir Cell Mol Biol 2010;42:716724.

29 Grassme H, Henry B, Ziobro R, Becker KA, Riethmuller J, Gardner A, Seitz AP, Steinmann J, Lang S, Ward C, Schuchman EH, Caldwell CC, Kamler M, Edwards MJ, Brodlie M, Gulbins E: beta1-Integrin Accumulates in Cystic Fibrosis Luminal Airway Epithelial Membranes and Decreases Sphingosine, Promoting Bacterial Infections. Cell Host Microbe 2017; DOI:10.1016/j.chom.2017.05.001.

30 Teichgraber V, Ulrich M, Endlich N, Riethmuller J, Wilker B, De Oliveira-Munding CC, van Heeckeren AM, Barr ML, von Kurthy G, Schmid KW, Weller M, Tummler B, Lang F, Grassme H, Doring G, Gulbins E: Ceramide accumulation mediates inflammation, cell death and infection susceptibility in cystic fibrosis. Nat Med 2008;14:382-391.

31 Beckmann N, Sharma D, Gulbins E, Becker KA, Edelmann B: Inhibition of acid sphingomyelinase by tricyclic antidepressants and analogons. Front Physiol 2014;5:331.

32 Morioka N, Suekama K, Zhang FF, Kajitani N, Hisaoka-Nakashima K, Takebayashi M, Nakata Y: Amitriptyline up-regulates connexin43-gap junction in rat cultured cortical astrocytes via activation of the p38 and c-Fos/AP-1 signalling pathway. Br J Pharmacol 2014;171:2854-2867. 


\section{Cellular Physiology and Biochemistry}

Cell Physiol Biochem 2019;52:565-579

33 Wisler JR, Springer AN, Hateley K, Mo XM, Evans DC, Cook CH, Gerlach AT, Murphy CV, Eiferman DS, Steinberg SM, Bergese SD, Papadimos TJ, Stawicki SP: Pre-injury neuro-psychiatric medication use, alone or in combination with cardiac medications, may affect outcomes in trauma patients. J Postgrad Med 2014;60:366-371.

34 Lee SM, Hutchinson M, Staikopoulos V, Saint DA: Amitriptyline pharmacologically preconditions rat hearts against cardiac ischemic-reperfusion injury. Int J Cardiol 2015;190:353-359.

35 Barbui C, Hotopf M: Amitriptyline v. the rest: still the leading antidepressant after 40 years of randomised controlled trials. Br J Psychiatry 2001;178:129-144.

36 Fangmann P, Assion HJ, Juckel G, Gonzalez CA, Lopez-Munoz F: Half a century of antidepressant drugs: on the clinical introduction of monoamine oxidase inhibitors, tricyclics, and tetracyclics. Part II: tricyclics and tetracyclics. J Clin Psychopharmacol 2008;28:1-4.

37 Moore RA, Derry S, Aldington D, Cole P, Wiffen PJ: Amitriptyline for neuropathic pain in adults. Cochrane Database Syst Rev 2015; DOI:10.1002/14651858.CD008242.pub3.

38 Moore RA, Derry S, Aldington D, Cole P, Wiffen PJ: Amitriptyline for neuropathic pain and fibromyalgia in adults. Cochrane Database Syst Rev 2012;12:CD008242.

39 Viera AJ, Hoag S, Shaughnessy J: Management of irritable bowel syndrome. Am Fam Physician 2002;66:1867-1874.

40 Leentjens J, Kox M, van der Hoeven JG, Netea MG, Pickkers P: Immunotherapy for the adjunctive treatment of sepsis: from immunosuppression to immunostimulation. Time for a paradigm change? Am J Respir Crit Care Med 2013;187:1287-1293. 